Revista Destaques Acadêmicos, Lajeado, v. 11, n. 4, 2019. ISSN 2176-3070

DOI: http://dx.doi.org/10.22410/issn.2176-3070.v11i4a2019.2134

http://www.univates.br/revistas

\title{
AVALIAÇÃO DO PROCESSO DE VERMICOMPOSTAGEM EM SOLO CONTENDO FÁRMACO CEFALEXINA
}

\author{
Lucélia Hoehne, Camila Roberta de Castro, Daniel Kuhn, \\ Ytan Andreine Schweizer, Sabrina Grando Cordeiro
}

Resumo: É de grande preocupação o estado em que se encontra o meio ambiente com relação à poluição. Uma nova classe de poluentes está chamando a atenção dos pesquisadores e órgãos governamentais, chamadas de micropoluentes emergentes, preocupantes por serem substâncias tóxicas capazes de gerar danos ao meio ambiente mesmo em pequenas quantidades. Uma das classes de micropoluentes são os fármacos, entre eles, estão os antibióticos, consumidos tanto por medicina humana como medicina veterinária. Para a indicação da presença de alteração ambiental, podem ser usados organismos vivos, chamados de bioindicadores ou indicadores biológicos. As minhocas são consideradas bioindicadores da qualidade do solo realizando também o processo de vermicompostagem, usado para a degradação da matéria orgânica. Assim, o objetivo do trabalho foi avaliar o efeito do antibiótico cefalexina em processo de vermicompostagem, utilizando minhocas da espécie Eisenia andrei. Foram feitos minhocários em pequena escala, com solo contendo o antibiótico, nas concentrações de $250 \mathrm{mg} / \mathrm{kg}$, $500 \mathrm{mg} / \mathrm{kg}$ e $1000 \mathrm{mg} / \mathrm{kg}$, monitorados por um período de 4 meses. Os parâmetros analisados no solo foram sódio, potássio, nitrogênio e $\mathrm{pH}$ do húmus gerado pelo processo de vermicompostagem. Já para as minhocas avaliou-se a biomassa, reprodução, fuga e mortalidade. Como resultado, foi possível observar que não houve alteração nos parâmetros analisados. Conclui-se que o antibiótico cefalexina, nas concentrações testadas, não alterou a reprodução e biomassa das minhocas, bem como a qualidade de húmus gerado.

Palavras-chave: vermicompostagem, cefalexina, bioindicador, Ensenia andrei.

\section{Introdução}

A poluição ambiental pode ser considerada como a degradação do ambiente, tendo como consequências atividades que prejudicam a saúde, a segurança e o bem-estar de todos os seres vivos. Existem vários tipos de poluições, como do ar, água e solo, podendo ocorrer de diversas formas: física, química, bioquímica, biológica e radioativa. Essa poluição acontece pela presença de toda a forma de matéria ou energia lançadas ou liberadas na natureza (DERISIO, 2017). 
Nas últimas décadas, uma nova classe de poluentes está chamando a atenção de pesquisadores e órgãos governamentais: os micropoluentes emergentes. Os micropoluentes emergentes, assim chamados, podem ser fármacos, agrotóxicos, produtos de cuidados pessoais e interferentes endócrinos que possuem propriedades persistentes e bioacumulativas, podendo promover alterações na síntese, secreção, metabolismo ou ação hormonais de organismos (GAMA, 2012; SOUZA 2011).

São considerados fármacos todas as classes de antibióticos, hormônios, anestésicos e anti-inflamatórios, entre outros. Dentre estes contaminantes, estudos revelam que aproximadamente $15 \%$ dos fármacos encontrados no meio ambiente são da classe dos antibióticos (ARAUJO et al., 2010). Para Kümmerer (2001), os antibióticos merecem uma atenção especial, pois sua disposição no ambiente de forma inadequada pode resultar no desenvolvimento de bactérias resistentes ao tratamento dos mesmos. Segundo Mulroy (2001), parte do fármaco ao ser ingerido, é excretado em sua forma original e bioativa, depositando no meio ambiente $50 \%$ a $90 \%$ de sua substância. Essas substâncias podem não ser removidas pelas estações de tratamento de esgoto (ETEs) em sua forma original, pois os tratamentos convencionais apresentam limitações na remoção destes compostos (BILA e DEZOTTI, 2003).

A Cefalexina é um antibiótico a-lactâmico, levemente solúvel na água e possui alta permeabilidade, de comprimido revestido e cápsula, por diferentes laboratórios farmacêuticos, muito utilizada na medicina para combater vários tipos de infecções bacterianas. No Brasil, é extensa a comercialização dos antibióticos contendo o fármaco cefalexina. $\mathrm{O}$ mau uso ou o uso excessivo desse medicamento pode resultar em um aumento da resistência bacteriana o tornado ineficaz no tratamento das infecções (PAULA, ALMEIDA \& CASSELLA, 2010; KASIM et al., 2004). Além disso, o descarte inadequado desse antibiótico pode prejudicar o meio ambiente. Para monitorar o grau de poluição, uma alternativa é o uso de bioindicadores. Estes, também chamados de indicadores biológicos são organismos vivos, que se alteram quando entram em contato com compostos xenobióticos (compostos sintetizados quimicamente, que não ocorrem naturalmente). Esses compostos, ao interagir com os seres vivos, são capazes de causar várias alterações que podem gerar desequilíbrios ecológicos, tais como alterações no comportamento, malformações, mudanças nas taxas de crescimento, reprodução, alimentação, alterações bioquímica e fisiológica (ARIAS et al.,2007).

As minhocas podem ser consideradas indicadores da qualidade do solo. Minhocas da espécie Eisenia andrei são utilizadas como bioindicadores, pois sobrevivem em uma ampla variação de temperatura, possui elevados índices de reprodução e maior ganho de biomassa. Esta espécie de minhoca também é muito utilizada no processo de vermicompostagem, devido a sua capacidade de converter resíduos de matéria orgânica em produtos como chorume e húmus (RIBEIRO et al., 2012; SCHIEDECK, 2010; NADOLNY, 2009). Um teste rápido 
que pode ser feito, para verificar se já ocorre efeito agudo no solo, é o chamado teste de fuga, que consiste em um recipiente contendo uma quantidade de solo contaminada e uma mesma quantidade de solo sem contaminação, separados por uma divisória. Minhocas são adicionadas e monitoradas por 48 horas, observando a comodidade no lado contaminado ou a fuga dele com a presença no lado não contaminado (HOEHNE et al., 2017; ISO 17512-1, 2008).

Assim, o objetivo deste trabalho foi avaliar o comportamento das minhocas geradas em processo de vermicompostagem em solo contendo o fármaco cefalexina, bem como a qualidade do vermicomposto gerado.

\section{Metodologia}

\subsection{Teste de fuga}

Foi realizado teste de fuga com quatro concentrações diferentes do fármaco cefalexina. O teste contou com as concentrações de $125 \mathrm{mg} / \mathrm{kg}, 250$ $\mathrm{mg} / \mathrm{kg}, 500 \mathrm{mg} / \mathrm{kg}$ e $1000 \mathrm{mg} / \mathrm{kg}$ do fármaco para cada $200 \mathrm{~g}$ de solo dividido por uma divisória em potes plásticos de $3 \mathrm{~L}$, onde metade do pote $(100 \mathrm{~g}$ do solo) continham o fármaco e a outra metade (100 g de solo) não continha a presença do fármaco. As divisórias foram removidas, em seguida adicionadas 10 minhocas adultas. Após o período de $24 \mathrm{~h}$ foi feito a verificação do solo e observado se houve migração das minhocas para o solo contendo ou não o micropoluente.

\subsection{Montagem dos minhocários}

Para garantir matéria orgânica como alimento para as minhocas, uma mistura de solo, esterco e serragem em uma proporção de 45:45:10, respectivamente, foi feita e distribuída nos minhocários. Para montar os minhocários foram utilizados recipientes plásticos, nas dimensões de $29 \mathrm{~cm}$ de comprimento, $12 \mathrm{~cm}$ de largura e $15 \mathrm{~cm}$ de altura (Figura 1). Todos os materiais foram misturados de forma homogênea, e em seguida foi adicionado o antibiótico cefalexina em três concentrações diferentes, de $250 \mathrm{mg} / \mathrm{kg}, 500$ $\mathrm{mg} / \mathrm{kg}$ e $1000 \mathrm{mg} / \mathrm{kg}$. A umidade do minhocários foi mantida em $50 \%$, com a adição de água. Para fins de monitoramento, foram feitos minhocários com a mesma mistura de matéria orgânica, porém, sem a adição do fármaco. Para cada minhocário foram selecionadas 10 minhocas adultas da espécie Eisenia andrei. Os testes foram realizados em triplicata. 
Figura 1: Minhocários com diferentes concentrações do fármaco cefalexina.

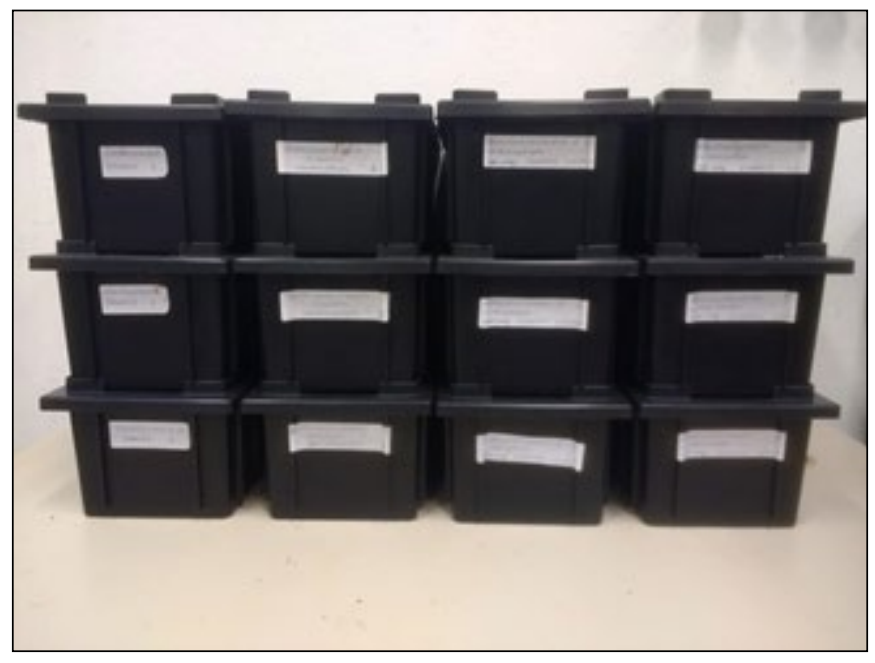

Fonte: Dos autores.

\subsection{Monitoramento das minhocas.}

As minhocas foram monitoradas semanalmente por um período de 6 meses (entre fevereiro e junho de 2018). Foi avaliado se houve fuga ou mortalidade, reprodução (número de ovos) e biomassa.

\subsection{Análise do húmus}

A qualidade do húmus gerado pelo processo de vermicompostagem foi monitorado pelas análises de $\mathrm{pH}$, fósforo $(\mathrm{P})$, nitrogênio $(\mathrm{N})$ e potássio $(\mathrm{K})$, conforme Manual de Métodos de Análise de Solo da Embrapa (EMBRAPA, 1997).

\subsection{1 $\mathrm{pH}$}

Transferiram-se cerca de $10 \mathrm{~mL}$ de húmus para béquer e adicionaram-se $25 \mathrm{~mL}$ de solução de $\mathrm{CaCl}_{2}$,, $01 \mathrm{M}$. Homogeneizou a amostra e após repouso de uma hora, realizou a leitura com pHmetro.

\subsubsection{Fósforo assimilável}

Fósforo assimilável corresponde a uma fração do teor total de fósforo $(\mathrm{P})$, e corresponde ao teor utilizado pelas plantas. Tem como princípio a formação de complexo fósforo-molíbdico de cor azul obtido após redução do molibdato com ácido ascórbico e determinação por Espectrometria de absorção molecular na região do ultravioleta/visível. Dessa forma, 5 gramas do húmus 
foram transferidos para erlenmeyer de $125 \mathrm{~mL}$, e adicionados $50 \mathrm{~mL}$ de solução extratora $\left(\mathrm{HCl} 0,05 \mathrm{~N} \mathrm{e} \mathrm{H}_{2} \mathrm{SO}_{4} 0,025 \mathrm{~N}\right)$. As amostras foram agitadas por 5 minutos em agitador circular horizontal. Deixou-se decantar por uma noite e após pipetaram-se $5 \mathrm{~mL}$ para erlenmeyer de $125 \mathrm{~mL}$. Adicionaram-se $10 \mathrm{~mL}$ de solução ácida de molibdato de amônio diluída e aproximadamente $30 \mathrm{mg}$ de ácido ascórbico em pó, como redutor. Após agitação de dois minutos, deixouse desenvolver cor por uma hora e em seguida realizou-se leitura da densidade óptica no comprimento de onda de $660 \mathrm{~nm}$. Para a obtenção dos resultados, foi elaborada uma curva de calibração com concentrações de 0 a 50 ppm, e aplicouse a equação 1 :

$$
\mathrm{P}(\mathrm{mg} / \mathrm{kg})=\mathrm{L} \times \mathrm{Fp} \times 10
$$

\section{Onde:}

$\mathrm{L}=$ leitura da amostra;

$\mathrm{Fp}=$ coeficiente angular da reta (obtida através da leitura dos padrões para a curva de calibração).

\subsubsection{Nitrogênio total (NT)}

A determinação de NT foi realizada pelo método de Kjeldahl. O nitrogênio é convertido em sulfato de amônio através de oxidação por processo de digestão com uma mistura de $\mathrm{CuSO}_{4}, \mathrm{H}_{2} \mathrm{SO}_{4}$ e $\mathrm{Na}_{2} \mathrm{SO}_{4}$. Posteriormente em meio alcalino, resultante da adição de solução de $\mathrm{NaOH}$ a $30 \%$, o sulfato de amônio convertido da matéria orgânica libera amônia que, em câmara de difusão, é complexada em solução de ácido bórico contendo indicador misto, sendo finalmente determinado por acidimetria, com solução de $\mathrm{HCl}$.

\subsubsection{Potássio (K)}

A determinação de $\mathrm{K}$ foi realizada através da técnica de fotometria de chama. Primeiramente, as amostras de húmus foram digeridas em forno de micro-ondas. Para isso, 0,5 gramas de húmus foram transferidos para vaso de digestão e adicionaram-se $6 \mathrm{~mL}$ de ácido nítrico P.A. As amostras foram digeridas a uma temperatura de $180^{\circ} \mathrm{C}$ por 20 minutos. Após esse período, as amostras foram filtradas e transferidas para frascos adequados, e seu volume foi aferido. Em seguida, a leitura foi realizada em fotômetro de chama (Digimed, modelo DM-62).

Os resultados foram submetidos ao tratamento estatístico, usando a análise de variância (ANOVA), seguida de teste post hoc de Tukey com $p<0,05$. 


\section{Resultados e Discussões}

O teste de fuga foi realizado para observar a tolerância das minhocas quanto à exposição ao antibiótico cefalexina. Não foi observada qualquer alteração nas concentrações testadas, demonstrando dessa forma que as minhocas da espécie Eisenia andrei são tolerantes ao fármaco, ou seja, não migraram.

O monitoramento das minhocas através do seu peso e contagem de ovos podem ser observados na Figura 2 e na Tabela 1.

Figura 2: Biomassa das minhocas.

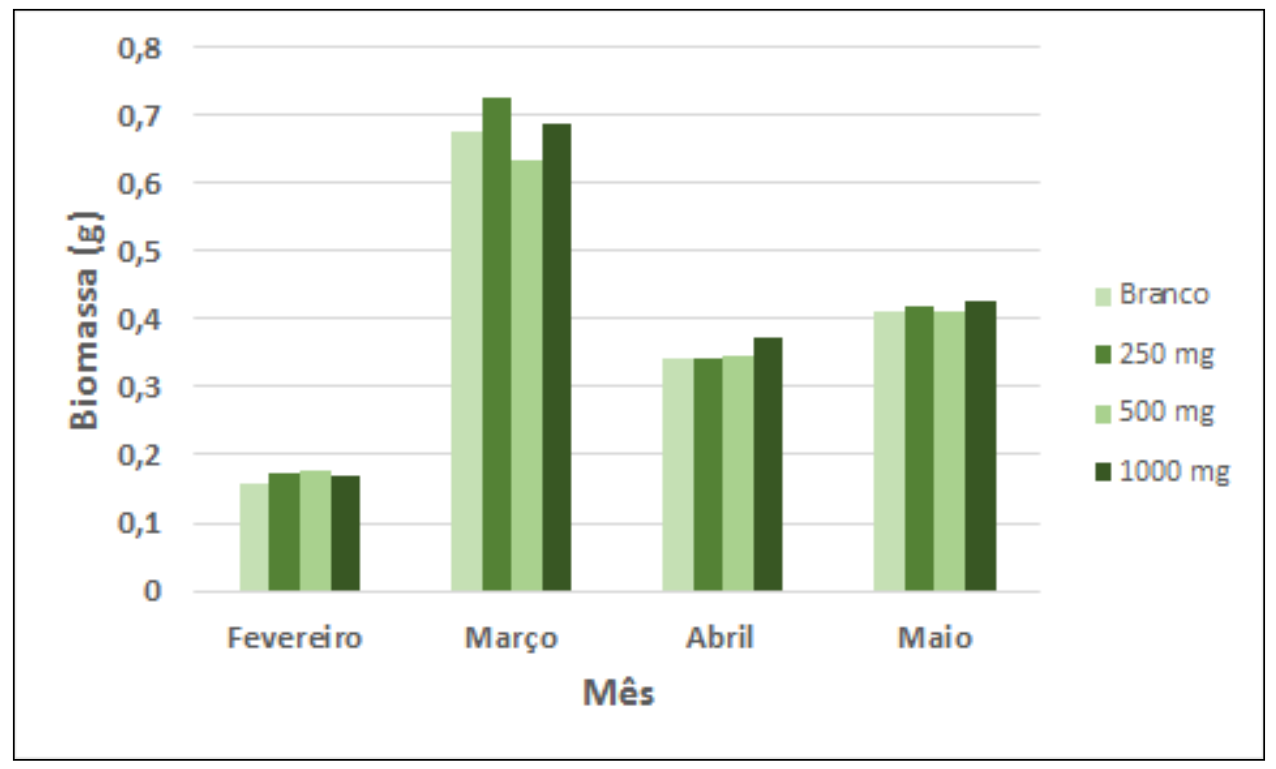

Tabela 1: Contagem de ovos.

\begin{tabular}{ccccc}
\hline \multirow{3}{*}{ Mês } & \multicolumn{4}{c}{ Concentração do fármaco } \\
\cline { 2 - 5 } & Branco & $250 \mathrm{mg} / \mathrm{kg}$ & $500 \mathrm{mg} / \mathrm{kg}$ & $1000 \mathrm{mg} / \mathrm{kg}$ \\
\hline Março & $125,0 \pm 12,0^{\mathrm{a}}$ & $126,7 \pm 12,4^{\mathrm{a}}$ & $125,7 \pm 2,4^{\mathrm{a}}$ & $131,0 \pm 12,0^{\mathrm{a}}$ \\
Abril & $14,7 \pm 1,5^{\mathrm{a}}$ & $12,3 \pm 1,3^{\mathrm{a}}$ & $9,3 \pm 1,0^{\mathrm{b}}$ & $14,7 \pm 3,0^{\mathrm{a}}$ \\
Maio & $1,0 \pm 0^{\mathrm{a}}$ & $1,0 \pm 0^{\mathrm{a}}$ & $1,0 \pm 0^{\mathrm{a}}$ & $1,0 \pm 0^{\mathrm{a}}$ \\
\hline
\end{tabular}

a,b letras iguais na mesma linha significa que não houve diferença estatística entre os resultados, com $\mathrm{P}<0,5$. 
De acordo com os resultados apresentados na Figura 2, pode ser observado que houve decréscimo do valor de biomassa no mês de abril. Isso também ocorreu com os resultados de reprodução, demonstrados na Tabela 1. Essa diferença ocorreu tanto para as minhocas em solo contendo o fármaco, como também com as minhocas no solo sem a adição do micropoluente. Este resultado provavelmente foi resultante da falta de alimento, não sendo relacionado à exposição do analito em questão. Cabe salientar que não foi considerado o mês de fevereiro para a comparação da massa (Figura 2), uma vez que foi o mês da incubação das minhocas, e consequentemente elas tiveram um aumento de massa até o mês de março.

Os resultados de $\mathrm{pH}$ e dos macronutrientes (potássio, nitrogênio e fósforo) estão demonstrados na Tabela 2.

Tabela 2: Valores obtidos da análise do húmus gerado pelo processo de vermicompostagem $(\mathrm{K}, \mathrm{N}, \mathrm{P}$ e $\mathrm{pH})$.

\begin{tabular}{ccccc}
\hline Parâmetro & Branco & $250 \mathrm{mg} / \mathrm{kg}$ & $500 \mathrm{mg} / \mathrm{kg}$ & $1000 \mathrm{mg} / \mathrm{kg}$ \\
\hline $\mathrm{pH}$ & $5,50 \pm 0,07^{\mathrm{a}}$ & $5,50 \pm 0,04^{\mathrm{a}}$ & $5,49 \pm 0,04^{\mathrm{a}}$ & $5,47 \pm 0,02^{\mathrm{a}}$ \\
$\mathrm{K}(\mathrm{mg} / \mathrm{g})$ & $1,14 \pm 0,03^{\mathrm{a}}$ & $1,11 \pm 0,08^{\mathrm{a}}$ & $1,15 \pm 0,04^{\mathrm{a}}$ & $1,13 \pm 0,08^{\mathrm{a}}$ \\
$\mathrm{N}(\mathrm{g} / \mathrm{kg})$ & $1,74 \pm 0,40^{\mathrm{a}}$ & $1,56 \pm 0,29^{\mathrm{a}}$ & $1,75 \pm 0,08^{\mathrm{a}}$ & $1,68 \pm 0,10^{\mathrm{a}}$ \\
$\mathrm{P}(\mathrm{g} / \mathrm{kg})$ & $0,37 \pm 0,01^{\mathrm{a}}$ & $0,38 \pm 0,01^{\mathrm{a}}$ & $0,38 \pm 0,01^{\mathrm{a}}$ & $0,39 \pm 0,01^{\mathrm{a}}$ \\
\hline
\end{tabular}

a,b letras iguais na mesma linha significa que não houve diferença estatística entre os resultados, com $\mathrm{P}<0,5$.

$\mathrm{O}$ pH e os macronutrientes K, N e P no solo, possuem grande importância para a nutrição das plantas por ajudar no processo fotossintético, função fisiológica e metabólica (ANDRADE et al., 2000). Conforme resultados da Tabela 2, não foi possível observar mudanças nos testes realizados com húmus produzidos nos minhocários contaminados em relação aos não contaminados (branco). Esse resultado sem mudanças encontra-se em todas as análises feitas.

Outros trabalhos também realizaram estudos monitorando reações de minhocas expostas a micropoluentes e a utilização da vermicompostagem como processo de degradação de algumas substâncias. Cotta (2008) verificou o húmus produzido pela minhoca gerada em solo contendo $2 \%(\mathrm{v} / \mathrm{v})$ de diesel, ou seja, uma concentração não letal para as minhocas. Constatou-se a remoção dos contaminantes do diesel (hidrocarbonetos policíclicos aromáticos - HPAs) tornando a técnica da vermicompostagem indicada para o processo. Candello (2014) avaliou o comportamento das minhocas da espécie Eisenia andrei em contato com antimicrobiano sulfadiazina (fármaco veterinário), através do teste de fuga. $\mathrm{O}$ autor não observou resposta de fuga evidente, ressaltando que fatores edáficos como $\mathrm{pH}$, microbiota, composição do solo e propriedades 
relativas à sorção, podem alterar a toxicidade das sulfonamidas, quimicamente anfóteras.

Hoehne et al. (2017) aplicou em cultivos de rúculas, húmus gerado em vermicompostagem contendo resíduo tratado de indústria de curtume com a intenção de reaproveitamento. Nestes resíduos está presente o metal tóxico cromo $(\mathrm{Cr})$. Após a passagem desse resíduo em vermicompostagem, o Cr teve redução de $128 \mathrm{mg} / \mathrm{kg}$ para $96 \mathrm{mg} / \mathrm{kg}$ e as concentrações de $\mathrm{N}, \mathrm{P}$ e K não se alteraram. Primaz et al. (2017) também avaliou o processo de vermicompostagem na decomposição de resíduos. Foi utilizado solo contendo óleo lubrificante usado, com o propósito de avaliar a recuperação do solo. Avaliaram-se parâmetros de $\mathrm{pH}, \mathrm{N}, \mathrm{P}, \mathrm{K}$, umidade e Hidrocarboneto Total de Petróleo. Os resultados indicaram aumentos nos teores de $\mathrm{P}$ e $\mathrm{K}$ e na umidade indicando melhor qualidade do solo contaminado após o processo de vermicompostagem.

\section{Conclusão}

Diante dos resultados apresentados, pode-se concluir que o solo com o fármaco cefalexina, nas concentrações testadas, não alterou o comportamento das minhocas, quanto ao seu desenvolvimento, assim como na reprodução, fuga e mortalidade. $\mathrm{O}$ teor de macronutrientes presentes no húmus gerado no processo de vermicompostagem não apresentou diferença entre as concentrações de cefalexina testadas.

A utilização de bioindicadores é uma importante ferramenta para avaliar a contaminação ambiental. Trabalhos futuros podem, além de avaliar o comportamento das minhocas no solo com cefalexina, avaliar também o percentual de remoção desse fármaco do solo após a vermicompostagem e monitorar as próximas gerações de filhotes das minhocas expostas ao micropoluente, para verificar seus possíveis efeitos a médio prazo.

\section{Agradecimentos}

O presente trabalho foi realizado com apoio da Coordenação de Aperfeiçoamento de Pessoal de Nível Superior - Brasil (CAPES) - Código de Financiamento 001, Conselho Nacional de Desenvolvimento Científico e Tecnológico (CNPq) e a Univates.

\section{Referências}

ANDRADE, Alex Carvalho; FONSECA, Dilermando Miranda da; GOMIDE, José Alberto; ALVAREZ V, Victor Hugo; MARTINS, Carlos Eugênio; SOUZA, Daniel Pacífico Homem de. Produtividade e valor nutritivo do Capim-elefante cv. Napier sob Doses Crescentes de Nitrogênio e Potássio. Revista Brasileira de Zootecnia. v. 29, n. 6, p. 1589 - 1595, 2000. 
ARAÚJO, Cleide S. T. MELO, Edmar I. ALVES, Vanessa N. COELHO, Nívia M. M. Moringa oleifera Lam. Seeds as a natural solid adsorbent for removal of agi in aqueous solutions. Journal Brazilian Chemical Society, v. 21, p. 1727-1732, 2010.

ARIAS, Ana Rosa Linde; BUSS, Daniel Forsin; ALBURQUERQUE; Carla de; INÁCIO, Alan Ferreira; FREIRE, Marina Moreira; EGLER Mariana; MUGNAI, Riccardo;

BAPTISTA, Darcilio Fernandes. Utilização de bioindicadores na avaliação de impacto e no monitoramento da contaminação de rios e córregos por agrotóxicos. Ciências \& Saúde Coletiva, p. 61-72, 2017.

BILA, Daniele M. DEZOTTI, Márcia; Fármacos no meio ambiente. Química Nova, v.26, n. 4, p. 523-530, 2003.

COTTA, Jussara Aparecida de Oliveira; Aplicação da vermicompostagem para a biorremediação de solos contaminados por hidrocarbonetos policíclicos aromáticos. 2008. Tese (Doutorado em Ciências - Química Analítica) - Instituto de química de São Carlos, Universidade de São Paulo, São Carlos, 2008.

DERISIO, José C. Introdução ao controle de poluição ambiental. $5^{\text {a }}$ edição, editora Oficina de textos, São Paulo, SP; 2017.

EMBRAPA. Centro Nacional de Pesquisa de Solos. Manual de Métodos de análise de solo / Centro Nacional de Pesquisa de Solos. 2a ed. Rev atual. Rio de Janeiro, RJ, 1997.

GAMA, Mariana R. Processos Fenton como alternativa na remoção de interferentes endócrinos e outros micropoluentes ambientais. Revista Virtual de Química, v.4, n.6, p. 777-787, 2012.

HOEHNE, Lucélia; SCHMALZ, Franciele Raquel; FREITAS, Elisete Maria de; KUHN, Daniel; ETGETON, Henrique Pretto; CARLESSO, Wagner Manica; DALLAZEN Maria Cristina; ORLANDI, Carla Roberta; BRUXEL, Fernanda; SANTOS, Rafael Pinto dos; PICOLOTTO, Aluisie; GIOVANELLA, Cristiano; ETHUR, Eduardo Miranda; Aplicação da vermicompostagem no resíduo tratado de indústria de curtume para cultivo de rúculas. Revista Destaques Acadêmicos, v. 9, n. 4, 2017.

ISO 17512-1. Soil quality - Avoidance test for testing the quality of soils and effects of chemical on behaviour - Part 1: Test with earthworms (Eisenia fetida and Eisenia andrei). ISO (International Organization for Standardization). Geneva, 2008.

KISIM, Neahl A. et al;. Molecular properties of WHO essential drugs and provisional biopharmaceutical classification. Molecular Pharmaceutics. v.1, n.1, p.85-96, 2004.

KÜMMERER, Klaus; Drugs in the environment: emission of drugs, diagnostic aids and disinfectants into wastewater by hospitals in relation to other sources - a review. Chemosphere. v. 48, n. 3, p. 957-969, 2001.

MULROY, Ashley. Monitoring and analysis of water and wastes. Water Environment Technology, v. 13, n. 2, p. 32-36, 2001. 
NADOLNY, Herlon S. Reprodução e desenvolvimento das minhocas (Eisenia andrei Bouché 1972 e Eudrilus eugeniae (Kinberg 1867)) em resíduo orgânico doméstico. 2009. Dissertação (Mestrado em Ciência do Solo) - Universidade Federal do Paraná, Curitiba, PR, 2009.

PAULA, Carlos E. de. ALMEIDA, Vanessa; CASSELLA, Ricardo; Determinação espectrofotométrica de cefalexina em formulações farmacêuticas explorando a sua reação de transferência de carga com a quinalizarina. Química Nova, v.33, n.4, p. 914919, 2010.

RIBEIRO, Rosecler. HOEHNE, Lucélia; CARLESSO, Wagner M. ETHUR, Eduardo M. STÜLP, Simone; A absorção de cobre por minhocas da espécie Eisenia andrei em solos e húmus contaminados. Revista Destaques Acadêmicos, v.4, n.4, 2012.

SCHIEDECK, Gustavo. Espécies de minhocas para minhocultura. 2010. Disponível em: <http://www.infobibos.com/artigos/2010_4/minhocultura/index.htm> . Acesso em: 24 fev. 2019.

SOUZA, Neyliane C. de. Avaliação de micropoluentes emergentes em esgotos e águas superficiais. 2011166 f. Tese (Doutorado em Engenharia Civil - Saneamento Ambiental) - Centro de Tecnologia, Universidade Federal do Ceará, Fortaleza, 2011. 